\title{
Growing information asymmetries as the cloud spreads
}

\author{
Primavera De Filippi \\ Research and Studies Center of Administrative Science (CERSA/CNRS), Université Paris /I \\ (Panthéon-Assas), France
}

Published on 22 Aug 2013 | DOI: 10.14763/2013.3.192

\begin{abstract}
To the extent that they provide content or information to the public, many cloud operators can be regarded as infomediaries - information intermediaries between users looking for information and the supplier of that information. As a general rule, 'infomediaries' are considered to be neutral providers of information. People often believe that the information they provide is unbiased, as they do not act on behalf of any third-party supplier or vendor, nor do they try to promote any type of information over the other. However, this situation is seldom true in the context of cloud computing, as many cloud operators have the discretionary power to decide exactly what kind of information is made available to the public and how that information is presented. While there are many ways in which this could affect the experience (and satisfaction) of end-users, this article analyses how hierarchies of information curation and distribution fundamentally challenge the user's right to access to information.
\end{abstract}

Keywords: Cloud computing, Infomediary, User-generated content, Freedom of expression, Information bias, Censorship

\section{Article information}

Received: 24 Jul 2013 Reviewed: 12 Aug 2013 Published: 22 Aug 2013

Licence: Creative Commons Attribution 3.0 Germany

Competing interests: The author has declared that no competing interests exist that have influenced the text.

URL: http://policyreview.info/articles/analysis/growing-information-asymmetries-cloud-spreads

\section{INFORMATION OVERLOAD1 AND THE ADVENT OF INFOMEDIARIES2}

The advent of internet and digital technologies allowed for a large amount of information to be reproduced and redistributed worldwide, in no time and at virtually no cost. The deployment of new tools and techniques for digital production also made it easier for people to produce information by their own means (UGC) and to improve or remix previously available 
information. This corresponds to what Lawrence Lessig has described as the "read-write" nature of the internet (Lessig, 2006).

Yet, this exponential rise in information production (and reproduction) brought the issue of information overload to a whole new level. As users are exposed to an increasing amount of information coming from a variety of sources (e-mail, Facebook, Twitter, YouTube, chats, forums, blog posts, etc), they do not have enough time to consume all of the information they encounter. Hence, users have to decide - by themselves - which type of information is more valuable than other (Kovach \& Rosenstiel, 2010).

The huge amount of information available on the internet has therefore - somewhat paradoxically - come to be regarded more as a hurdle than as an opportunity (Lincoln, 2011). Indeed, the more information is available, the harder it gets for users to identify which content is actually valuable or trustworthy. As opposed to professionally produced content (i.e., content which has been commissioned by or for a particular entity that will supervise the quality thereof), most (but not all) of the user-generated content that can be found on the internet is, indeed, often inaccurate or deceptive - to the extent that there are no rules or controls over neither the quality nor the accuracy of such content.3 Valuable information can thus be overtaken or "contamined" by unsolicited and irrelevant information - so-called information pollution (Cameron \& Ju-Pak, 2000).

This is what motivated the emergence of infomediaries - information intermediaries between users looking for information and the supplier of that information - whose activities are mainly focused on retrieving information from a variety of sources, ranking it according to its value or relevance (according to objective or subjective criteria), and reorganising it in a way that is more appealing to end-users (Vervest \& $\mathrm{Al}$, 2000).

It is possible to distinguish between two main categories of infomediaries: information curators, on the one hand, which merely collect and aggregate content from different sources to display it in a more organised or accessible way on their own platform, often redirecting users to the original source of information (this is the case, for instance, of many newspapers, magazines, or other information portals - e.g., MSN, CNN.com, Google News, etc - as well as various price comparison websites - such as Expedia.com or BestPrice.com); and information creators on the other hand, which either collect information or provide a platform for users to submit information with a view to produce new, inferred information that will constitute the basis for a particular online service (this is the case of many commercial transaction portals, such as eBay.com, or mail order companies, such as Amazon.com).

Of course, this distinction is not clear-cut. Although several infomediaries will either belong to one or the other of these two categories, there are, in practice, many infomediaries that will situate themselves in the gray-area, insofar as they offer partly overlapping services and options: a large number of infomediaries concerned with information curation also accommodate a series of complementary services aimed at promoting or enriching the information they provide. Yet, this distinction represents nonetheless a useful theoretical framework to analyse the impact that the activities of different infomediaries could have on the user's right to freedom of expression.

This article analyses, specifically, how hierarchies of information curation and distribution fundamentally challenge the right of access to information. It focuses, therefore, exclusively on the former category of infomediaries, to the extent that they are the most likely to impinge upon these rights. Indeed, while most information creators are clearly driven by commercial interests 
and are therefore not expected to provide neutral, unbiased information, information curators are generally considered to be (relatively) neutral providers of information: news or information portals are only expected to be biased by the political position of the source, whereas comparison or rating websites are actually expected to reflect the "truth" (in terms of user rating or reviews).

\section{CLOUD OPERATORS : INFOMEDIARIES OR INFORMATION GATEKEEPERS4 ?}

Cloud operators are internet service providers that rely on cloud computing technologies to provide a series of online platforms which are available at any time and from anywhere. To the extent that they provide content or information to the public, many of these operators can be regarded as some kind of infomediaries.

Indeed, with more and more information invading the network, we observe, today, the emergence of a new typology of cloud services - like Reddit, Flickr, Storify or Bundlr - whose objective is not only to aggregate a maximum amount of information into one place, but also to collect high quality contributions from users, and subsequently encourage the community to tag, label, or organise them into specific categories. Oftentimes, these infomediaries also invite the community to evaluate or rank each other's contributions, so as to identify which ones are the most or the less valuable. This specific typology of infomediaries can be regarded as a particular subset of information curators, which essentially rely on the user community to "curate" the information they provide. They are, nowadays, assuming an increasingly important role on the internet, since - in a situation of information overflow - curation becomes a service with very high added-value.

Yet, while many people believe that these infomediaries are neutral - to the extent that they do not act on behalf of any third-party supplier or vendor, nor do they try to promote any type of information over the other - the truth is that the information provided by many cloud operators is fundamentally biased, by virtue of the discretionary power they have to decide exactly what kind of information is made available to the public and how that information is presented.

There are many ways in which bias can affect the production, distribution and curation of information, we will present here the ones that are the most likely to impair the fundamental right to freedom of expression and access to information.

Certain infomediaries (such as, for instance, the yellow pages for businesses, as well as many product reviews or recommendations websites) actually charge a fee for displaying information on their platform - a fee that is generally paid for by the information supplier. This necessarily creates a distortion in the kind of information provided by the infomediary, since paid content will naturally be favoured over non-paid content - regardless of the quality and/or relevancy thereof.

Another problem that is found in various community platforms that rely on user-generatedcontent is that the infomediaries can mix UGC with advertising, and present advertising as UGC in order to enhance its credibility. This is well illustrated by Facebook's new advertising policies allowing for brand page owners to advertise their products or services as sponsored stories (which are almost equivalent to standard Facebook ads), and - most importantly - the newly implemented feature allowing users to pay a fee so as to publish promoted posts - i.e., posts that 
will appear higher in the news feed, so as to increase the chances that the audience will see them.

In addition, several online operators arbitrarily chose to censor certain types of content that they consider either illegal or offensive. Facebook, again, is a good example of an online operator engaging in the practices of corporate censorship. While its terms of use stipulate that any content uploaded onto the platform that does not respect community standards will be categorically removed, Facebook has been many time accused of censoring content (e.g., certain kinds of political content, queer-related posts, or - most notably - photos of mothers breastfeeding their babies) without any reasonable justification.

The result is that, from mere infomediaries, many online operators are progressively turning into information gatekeepers: while they do not preclude access to information as such, they do have full discretion on the type of content that users may or may not see, and they can arbitrarily choose the way it will be presented onto their website (thereby affecting both its visibility and the way it will be perceived by end-users).

\section{THE RISE OF INFORMATION ASYMMETRIES}

Just like any other online services, in order to be sustainable over time, infomediaries need to derive an income from their services. Hence, although most of their revenues are extracted from online advertising rather than from access fees, certain infomediaries might only provide their services previous subscription. This is the case of most online services that distribute copyright protected content (such as Napster for music, Netflix for films, the New York Times for news article, JSTOR for scientific papers, etc). Interestingly, a few online aggregators (such as Yodlee for financial data, or Zillow for real estate information) require users to subscribe to their services before they can have access to the information they provide, even when such information is freely available on the internet. Thus, although access to information is not precluded per se, users are nonetheless excluded from enjoying the benefit of direct access to valuable information, presented in an easy and understandable way. As a result, sophisticated services of information curation and classification might not be available to those who do not have the means to pay for the subscription fees.

Of course, assuming competition in the market for infomediaries, one could expect that - as long as there is a demand for it - new infomediaries will emerge to fulfil the needs of the users who cannot afford, or are not willing to pay for the services of more expensive infomediaries.

The risk is, however, that, since they cannot extract any rent from these specific types of users, the services provided by these infomediaries will rely either on online advertising (e.g., by charging businesses to advertise their products or services on the platform), or - more critically on the subsidies that they received (either openly or concealed) by the information suppliers (this was, most notably, the business model employed by GoTo.com, a pay-for-placement search service which has now been acquired by Yahoo). This means that, while richer users will have access to well organised, unbiased, high quality information, poorer users will only be able to benefit from access to biased and often deceptive information - which ultimately constitutes a concealed type of advertisement.

Even worse, infomediaries might actually distort information in order to increase their own profits. Such was the case of Yelp $p^{\prime \prime}>$ http://yelp.com (an online service providing internet 
rating, customers' reviews and recommendations for local restaurants, shopping, nightlife, entertainment and more) whose reviews are filtered according to (allegedly objective) criteria which are, however, not publicly disclosed. In the past years, Yelp has been accused of manipulating the ranking of these reviews as an attempt to 'extort' businesses and increase its advertising revenues. 6 Yet, the case has eventually been decided in favour of Yelp, since none of the claimants had the ability to prove their accusations (i.e., given the lack of transparency as regards Yelp editorial practices, it was not possible to show that Yelp was indeed tampering with the results) and, to the extent that it qualifies as a content editor, Yelp was entitled to rely on "editorial immunity."

Conversely, assuming no, or little competition in the market, the risk is that some user will actually be excluded from certain types of content or information, unless they subscribe to the services of the dominant infomediary. This is the case, for instance, of many infomediaries that actually commission high quality content to be exhibited on their website (e.g., expert reports, featured articles, etc), as well as all those infomediaries that mainly rely on UGC in order to fill up their websites (such as Facebook, eBay, Yelp, etc). Users contributing to enhancing the information base of these dominant infomediaries are, in fact, unlikely to reproduce the same content on smaller and less popular platforms.

Overall, given the discretionary power of infomediaries over the way in which information is being provided and presented to users, there lies the risk that different people - depending on their level of education, social status, and financial resources - will have access to different types of information. A line can thus be drawn between the "information-riches", who have access to more valuable and sophisticated content, and "information-poors" who are only able to access the most "popular" content: content that is often being pushed to them (generally for free) by large corporations with a specific social, economic or political agenda (e.g., to further the interests of a particular social group, to maximise economic profits or financial returns, to support the ideas or to advocate for one political party, etc). Yet, these inequalities of information can be very subtle and often go unnoticed to most users.

\section{PROTECTING THE RIGHT OF ACCESS TO INFORMATION}

The right to freedom of expression has been outlined in Article 19 of the Universal Declaration of Human Rights, which stipulates that everyone has the right to freedom of opinion and expression; that this right includes freedom to hold opinions without interference, and to seek, receive or impart information and ideas through any media and regardless of frontiers.

Nowadays, with the advent of the internet and digital technologies, it has become easier for anyone to express their views and opinions and to disseminate them globally on the network. (Hague \& Loader, 1999). Of course, the availability of technical means to produce and distribute information does not necessarily mean that anyone can use them without incurring risks. Many authoritarian regimes (such as those in China, Syria or North Korea) are seriously restraining the use of the internet and are generally challenging the exercise of free speech, both online and offline (Kalathil \& Boas, 2010).

Yet, in most democratic countries where no such restrictions exist, the right to freedom of expression is nonetheless put at risk. The main issue no longer relates to the ability for people to express themselves, but rather to the need for people to access information equally: the right of access to information. In the context of internet and information technologies, this right 
essentially refers to the ability for users to access online content freely, i.e., without censorship or restrictions.

While much focus has been put on state censorship and filtering techniques (Deibert \& Villeneuve, 2004; Wu, 2006; Balkin, 2008), as well as on the growing impact of corporate censorship (Cohen, 2005; Lau \& Wines, 2005; Kreimer, 2006), little attention has been paid to the considerable influence that infomediaries could have on the way in which information is perceived by the public, and how this could affect the right of access to information.

Indeed, as more information becomes available on the internet, it becomes always harder for users to find the information they want, and - most importantly - to recognise that the information they are consuming is, indeed, the information they want. Infomediaries can partially resolve this problem by providing a pre-selection of information, classified into relevant categories, so as to be more easily found by end-users. Yet, the business model adopted by each infomediary will significantly affect the quality and the kind of information that will find its way to the user base. On the one hand, subscription services will most likely provide more relevant, unbiased and specialised information, since users pay to ensure quality and neutral handling by infomediaries. Free infomediation services will, on the other hand, need to secure another source of funding. Beyond relying on state funds (like public television or radio) or community funds (as Wikimedia, Indymedia, etc), free infomediary could either be funded by advertising revenues or subsidised by information providers who want their content to attain more visibility. In the two latter cases, the information provided will most likely be less relevant (given that it will have been less accurately selected), more popular (so as to attract more revenues from advertising) and - of course - more biased (since paid content will be promoted over unpaid content).

Thus, even though, on the internet, everyone has - theoretically - the same ability to access and consume information, infomediaries might actually contribute to rising the divide between the information-riches - who can pay for more sophisticated (and expensive) services of infomediation - and the information-poors - who cannot afford anything more than a free (and therefore more biased) service. The issue is even more problematic in the case of users who are less educated than others and who therefore do not even know what they are missing (since they might never have had proper access to quality information).

Information inequality constitutes nowadays an important concern with significant social, economic and political implications - which should therefore be properly taken into account by the law. Yet, while the right to freedom of expression (and the right of access to information) is a fundamental right that every citizen is entitled to, it can, however, only be enforced against governmental bodies, and a limited number of private actors.7

Consumer protection could, sometimes, be relied upon in order to preclude private entities from manipulating or distorting information rankings to their own benefit, at the detriment of consumer's ability to make a rational, well-informed choice.8 Yet, consumer protection can cover only those cases where citizens are affected as consumers (i.e., in their commercial interactions), whereas all aspects related to free speech affect individuals as citizens, not as consumers. Thus - as in the case of Yelp ${ }_{9}$ - to the extent that infomediaries actually qualify as "curators of information" (as opposed to mere hosts), they are entitled to rely on the doctrine of "editorial immunity" whenever they decide to censor or take down some of the content published by the user-base.

To conclude, it appears that precluding online infomediaries from infringing the user's right of 
access to information might actually be harder than expected. Beyond the law, other means could nonetheless be employed to resolve, or to reduce information inequality on the internet. These include, for instance: public knowledge production, curation and distribution; subsidies for content creation, curation and distribution by independent actors from civil society (e.g., independent broadcasters); media literacy empowering people to be their own filters; and, of course, more transparent and localised systems for ranking and classification (e.g., based on decentralised peer-to-peer techniques).

\section{FOOTNOTES}

1. The term information overload was popularised by Alvin Toffler (1970) in his book "Future Shock". It refers to the difficulty to access or understand information due to the presence of too much information.

2. The term infomediary was coined by John Hagel \& Jeffrey F. Rayport (1996) in their article entitled "The Coming Battle for Customer Information." It refers to any company or website that gathers information from various sources, and present it to consumer in an organised manner.

3. This is not to say that all user-generated-content is essentially low-quality, biased or inaccurate content. Indeed, Wikipedia is perhaps the best illustration of high-quality UGC that is often more accurate and less biased than its commercial counterparts. Yet, Wikipedia content is produced in a highly structured environment, with rules and procedures for review which are often lacking in the majority of user-generated-content platforms, such as YouTube or Blogster.

4. Shoemaker \& Vos (2009) define gatekeeping as the "process of culling and crafting countless bits of information into the limited number of messages that reach people everyday, and it is the center of the media's role in modern public life. [...] This process determines not only which information is selected, but also what the content and nature of the messages, such as news, will be."

5. Yelp Inc. is an American company that offers internet rating and review services including a directory service and review site with social networking features. More details on 6. See e.g., the case of Boris Levitt vs. Yelp, Inc. (March, 2010), where several businesses filed suit against Yelp, claiming that the site manipulated (and sometimes even manufactured) users' reviews in order to force businesses to advertise their services on the website.

7.: While a few countries have enacted freedom of information legislation that covers not only government bodies but also - to a limited degree - private bodies, those are generally sectoral legislations which only apply to private bodies operating in specific fields of endeavour.

8. The right of access to information has been endorsed since 1983 in the United Nations Guidelines for Consumer Protection adopted by the United Nations Commission on Transnational Corporations, which recognises, amongst other, the right for consumers "to access adequate information to enable making informed choices according to individual wishes and needs."

9. In Levitt v Yelp! Inc., No. C-10-1321 EMC (N.D. Cal. October 26, 2011), a class action was filed against Yelp, accused of unlawfully manipulating business' review pages, so as to induce them to pay for advertising. The action has been dismissed, as the court found that Yelp (as an editor) was entitled to decide on which user-generated reviews should be published or omitted on the website, so as to remain immune from potential liability arising from third-party contents - as stipulated by Section 230 of Communications Decency Act ("CDA"). 


\section{REFERENCES}

Balkin, J. M. (2008). Future of Free Expression in a Digital Age, The. Pepp. L. Rev., 36, 427.

Cameron, G. T., \& Ju-Pak, K. H. (2000). Information pollution. Newspaper Research Journal, 21(1), 65-76.

Cohen, E. D. (2005). News incorporated: Corporate media ownership and its threat to democracy. Pyr Books.

Deibert, R., \& Villeneuve, N. (2004). Firewalls and power: An overview of global state censorship of the Internet. Human rights in the digital age. London: GlassHouse.

Hagel, J., \& Rayport, J. F. (1996). The Coming Battle for Customer Information, Harvard Business Review, 1996.

Hague, B. N., \& Loader, B. D. (Eds.). (1999). Digital democracy: Discourse and decision making in the information age. Routledge.

Kalathil, S., \& Boas, T. C. (2010). Open networks, closed regimes: The impact of the Internet on authoritarian rule. Carnegie Endowment.

Kovach, B., \& Rosenstiel, T. (2010). Blur: How to know what's true in the age of information overload. Bloomsbury Publishing USA.

Kreimer, S. F. (2006). Censorship by proxy: the first amendment, Internet intermediaries, and the problem of the weakest link. University of Pennsylvania Law Review, 11-101.

Lau, T., \& Wines, W. (2005). Can You Hear Me Now? Corporate Censorship and Its Troubling Implications for the First Amendment. DePaul Law Review,55(1), 119-168.

Lessig, L. (2006). The read-write society. A keynote given, 15.

Lincoln, A. (2011). FYI: TMI: Toward a holistic social theory of information overload. First Monday, 16(3).

Shoemaker, P. J., \& Vos, T. (2009). Gatekeeping theory. Routledge

Vervest, P., \& Al, D. (2000). How to win customers in the digital world: total action or fatal inaction. Springer.

Wu, T. (2006). World Trade Law of Censorship and Internet Filtering, The. Chi. J. Int'l L., 7, 263. 